\title{
Study on the Charge Parameters of Explosive Seismic Exploration Used in Carbonate Strata
}

\author{
Hong-Chao SHI ${ }^{1, a,{ }^{*},}$ Ji-Chun ZHANG $^{1, a}$ Zhong-Ping WEN ${ }^{2, a}$ \\ ${ }^{1}$ Southwest Jiao Tong University School of Civil Engineering, Chengdu, Sichuan, China \\ ${ }^{2}$ CNPC Chuanqing Drilling engineering, Ltd Geophysical Exploration Company Chengdu, Sichuan, \\ China
}

a727722750@qq.com

${ }^{*}$ Corresponding author

Keywords: Explosive Seismic Exploration, Charge Parameters, Dynamic Numerical Simulation.

\begin{abstract}
As one of the major methods used for geophysical exploration, Seismic exploration applies the propagation law of explosion excitation seismic waves in different strata to detect geological conditions underground. The vibration characteristics of explosion excitation seismic waves will influence the quality of the reflection or refraction waves produced by strata interface while received by the earth surface. The vibration characteristics of seismic waves caused by explosion excitation in strata are influenced by many factors, such as the self-identities of explosive, the geometrical shape and structure of explosive package, the buried depth and lithological characters of strata for explosive excitation, etc. In order to improve the signal-to-noise ratio of seismic exploration work in the area of carbonate stratum, this paper focuses on the research into the vibration characteristics of explosive seismic waves in carbonate strata caused by the specialized explosives with standard explosive package (the detonation velocity is $5300 \mathrm{~m} / \mathrm{s}$, the density is $1.6 \mathrm{~g} / \mathrm{cm}^{3}$, the diameter of the columnar explosive package is $5.0 \mathrm{~cm}$ ). Dynamic numerical simulation method and General explicit dynamic analysis program LS-DYNA are used to explore the optimum parameters of a single explosive package in a single excitation well. The applicable weight and minimum buried depth of standard explosive package in carbonate strata can be determined by comparing and analyzing the vibration waveforms and strengths of the monitoring points, the results of the numerical simulation tests performed with explosive packages of different weights at one same buried depth and with explosive packages of the same weight at different buried depths. The results show that: 1.Increasing only the weight of standard explosive package has limited effects on promoting the strength of seismic waves just below the package.2. When the buried depth of standard explosive package is less than $4 \mathrm{~ms}$, the reflected waves from the upper free surface will influence the seismic waves transmitted downward by the explosive package, and may possibly change the characteristics of the seismic waves' forms. With the increase of the buried depth, the influence of the reflected waves from the upper free surface will gradually weaken. 3.With the application of the method of a single explosive package in a single excitation well to explosion excitation, the weight of explosive package should be in the range of $4 \mathrm{~kg} \sim 8 \mathrm{~kg}$, up to a maximum of $10 \mathrm{~kg}$ to ensure a higher gain efficiency of vibration. 4 . When the weight of standard explosive package is $10 \mathrm{~kg}$, the critical depth of burial in carbonate strata is $4 \mathrm{~m} \sim 6 \mathrm{~m}$ below the bedrock surface.
\end{abstract}

\section{Introduction}

Seismic exploration is one of the major methods used for geophysical exploration. When seismic waves of the excitation somewhere below the ground spread to the underground and encounter different elastic strata, they will generate reflected or refracted waves returning to the ground which can be recorded with specialized instruments. Analyzing the records obtained, such as the propagation time of the waves, vibration shapes, etc. will enable us to accurately measure the depths and shapes of the strata to determine their lithology.

The vibration characteristics of seismic waves caused by explosion excitation in strata are influenced by these factors, such as the nature of explosive charges, the physical dimension of explosive package, the 
structure of charge, the depth of burial and the lithological characters of strata for explosion excitation, etc. In order to improve the signal-to-noise ratio of seismic exploration work in the area of carbonate stratum, this paper focuses on the research into the vibration characteristics of explosive seismic waves in carbonate strata caused by the specialized explosives with standard explosive package (the detonation velocity is $5300 \mathrm{~m} / \mathrm{s}$, the density is $1.6 \mathrm{~g} / \mathrm{cm}^{3}$, the diameter of the columnar explosive package is $5.0 \mathrm{~cm}$ ). The study uses numerical simulation tests to research the applicable weight and the critical depth of burial in carbonate strata with standard explosive package.

\section{Numerical Simulation Test}

\section{Computational Methods}

During the numerical simulation test, the simplified $1 / 4$ numerical model was established based on the symmetry condition. As the focus of the study is the propagation law of seismic waves within the rock below the explosive package, the thickness of strata under the package is $50 \mathrm{~ms}$ in numerical model, radial size is $5 \mathrm{~ms}$, which is bigger than the range of Cylindrical Charge fissures circle (100 to 150 times of the explosive package radius). A typical numerical experiment used in the model is shown in Fig.1.

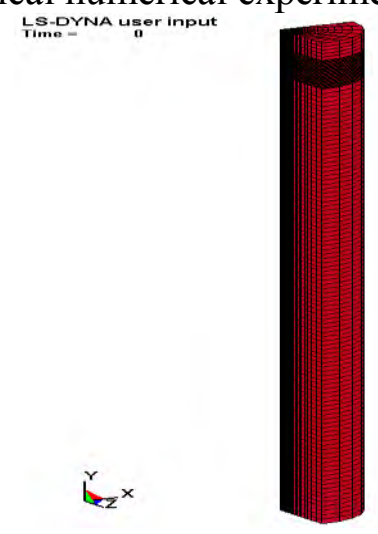

Fig. 1 Typical Numerical Model

MAT_HIGH_EXPLOSIVE_BURN material model is used to represent the explosive material and the equation of state for an explosive used in this study was Jones-Wilkins-Lee(JWL) equation.By using JWL equation of state and setting the denotation point and time of the explosive, the simulation of the detonation process of the explosive can be realized in the program.

JWL(Jones-Wilkins-Lee)Equation of state is shown in equation 1:

$$
P=A\left(1-\frac{\omega}{R_{1} V}\right) e^{-R_{1} V}+B\left(1-\frac{\omega}{R_{2} V}\right) e^{-R_{2} V}+\frac{\omega E}{V}
$$

In this equation, $\mathrm{A}, \mathrm{B}, R_{1}, R_{2}, \omega$ are constant, $\mathrm{E}$ is energy per unit volume of the explosive, $\mathrm{V}$ is relative volume, explosive parameters used in the calculation and JWL equation of state parameters are shown in Table 1.

MAT_PLASTIC_KINEMATIC material model is used to represent rock media material, and the rock parameters used in the computation are shown in Table 2.

Tab. 1 Explosive Parameters and Equation of State Parameters

\begin{tabular}{ccccccccccc}
\hline $\begin{array}{c}\text { Density } \\
\rho\end{array}$ & $\begin{array}{c}\text { Detonation } \\
\text { velocity } \\
\mathrm{D}\end{array}$ & $\begin{array}{c}\text { Detonation } \\
\text { pressure } \\
P_{c-j}\end{array}$ & $A$ & $B$ & $R_{1}$ & $R_{2}$ & $\omega$ & $E$ & $\begin{array}{c}\text { The initial } \\
\text { hematocri } \\
\mathrm{t} V_{0}\end{array}$ \\
\hline $\mathrm{g} / \mathrm{cm}^{3}$ & $\mathrm{~m} / \mathrm{s}$ & $\mathrm{GPa}$ & $\mathrm{GPa}$ & $\mathrm{GPa}$ & - & - & - & $\mathrm{MPa}$ & - \\
\hline 1.63 & 5300 & 530 & 317.2 & 3.23 & 4.15 & 0.95 & 0.3 & 70 & 0 \\
\hline
\end{tabular}


Tab. 2 The Main Physical Parameters of Rocks

\begin{tabular}{cccccc}
\hline $\begin{array}{c}\text { Density } \\
\rho\end{array}$ & $\begin{array}{c}\text { Modulus } \\
\mathrm{E}\end{array}$ & $\begin{array}{c}\text { Poisson's } \\
\text { ratio } \\
\mu\end{array}$ & Yield stress & Cohesion & $\begin{array}{c}\text { Internal friction } \\
\text { angle }\end{array}$ \\
\hline $\mathrm{g} / \mathrm{cm}^{3}$ & $\mathrm{GPa}$ & $\mathrm{Mbar}$ & $\mathrm{MPa}$ & $\mathrm{GPa}$ & $\left({ }^{\circ}\right)$ \\
\hline 2.6 & 48 & 0.22 & 60 & & \\
\hline
\end{tabular}

\section{Research on the Applicable Weight}

The weight change of explosive package will undoubtedly lead to the change of the vibration characteristics in Rock mass. Since the propagation velocity of explosion seismic wave within the rock is slower than the detonation speed, the length of cylindrical explosive package for downward propagation of seismic wave has the effectively superimposed effect of intensity and energy is limited. So merely increasing the weight of cylindrical explosive package can not achieve a satisfactory effect. Thus it is necessary to study how the seismic waves transmitted downward by explosion vary with the weight change of explosive package, which can provide the basis for the choice of applicable weight of a single explosive package in the exploration work.

To determine the influence mechanism of the weight of explosive package on the energy transmitted downward by explosive seismic waves, this paper does numerical calculations and analyses of nine situations in which explosive packages of different weights are used. The weights are $1 \mathrm{~kg}, 2 \mathrm{~kg}, 4 \mathrm{~kg}, 6 \mathrm{~kg}$, $8 \mathrm{~kg}, 10 \mathrm{~kg}, 15 \mathrm{~kg}, 20 \mathrm{~kg}$ and $25 \mathrm{~kg}$. Respectively, the calculation model boundary conditions are non-reflecting boundary.

Vibration monitoring point: $1 \mathrm{~m}$ below the explosive package and in $1 \mathrm{~m}$ radial direction, calculated results of unit explosive incremental vibration velocity gain rate with the change of package weight are shown in Fig.2.

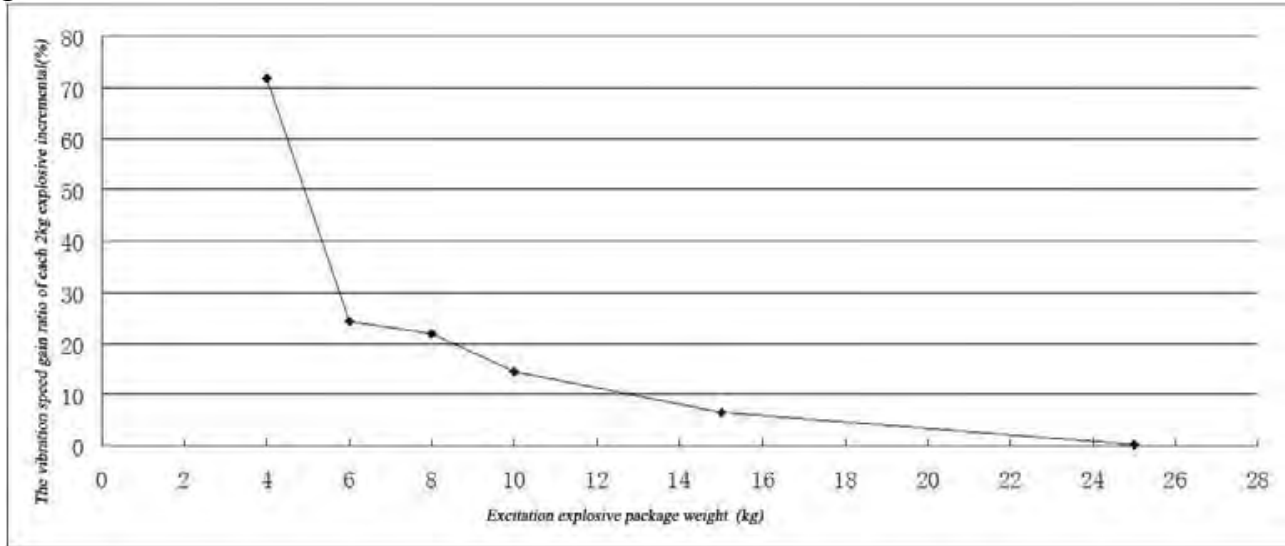

Fig. $21 \mathrm{~m}$ below the Explosive Package, $1 \mathrm{~m}$ at Rradial Vibration Monitoring point, Calculated Results of

Unit Explosive Incremental Vibration Velocity Gain Rate with the Change of Package Weight

In Fig.2, the relationship between the vibration speed gain ratio obtained with every $2 \mathrm{~kg}$ explosive incremental and the weight of excitation explosive package shows that when the excitation package weight increases from $2 \mathrm{~kg}$ to $4 \mathrm{~kg}$, the velocity gain ratio is up to approximately $72 \%$. However, when the package weight increases from $4 \mathrm{~kg}$ to $6 \mathrm{~kg}$, the velocity gain ratio greatly decreases to about $24 \%$. When the excitation package weight increases from $6 \mathrm{~kg}$ to $8 \mathrm{~kg}$, velocity gain ratio is about $21 \%$, almost flat with the previous stage. When the explosive package weight increases from $8 \mathrm{~kg}$ to $10 \mathrm{~kg}$, the vibration speed gain ratio further decreased to $14 \%$ and when the explosive package weight is over $8 \mathrm{~kg}$, the velocity gain ratio is only 1 to $6 \%$.

In order to consider the impact of action time t between explosive stress and rock, calculate a variety of different cases in explosive package weight, use impulse in the same location unit inside the model to measure the effect of the energy gain of the standard explosive package. Formula of impulse $I$ is shown in Equation 2. 


$$
I=\int_{0}^{t_{1}} P(t) \mathrm{d} t
$$

In this equation, is the unit function of pressure with time, $t_{1}$ is the duration of action time. Unit impulse results at $2.5 \mathrm{~m}$ below, $1 \mathrm{~m}$ radial of the explosive package is shown in Fig.3.

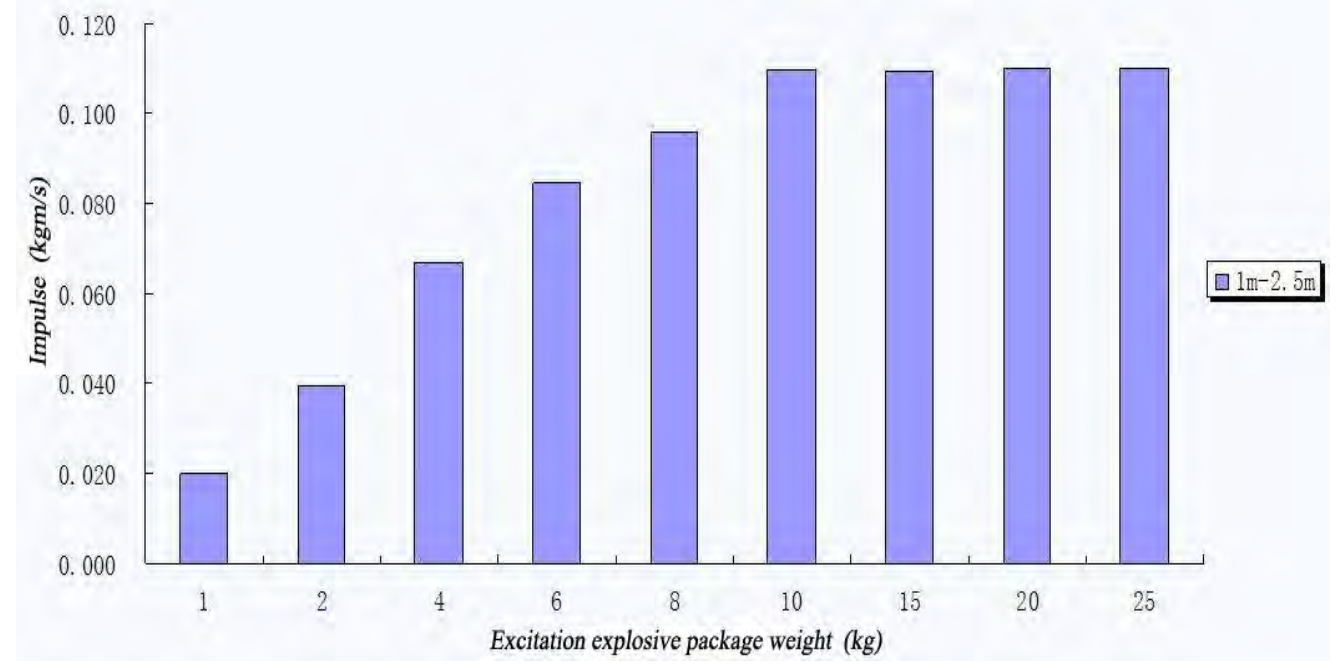

Fig.3 2.5m below, $1 \mathrm{~m}$ Radial of the Explosive Package Uunit Impulse Histogram

Fig. 3 shows that when the weight of package increases from $1 \mathrm{~kg}$ to $10 \mathrm{~kg}$, the energy of downstream seismic waves will increase with the increase of the weight of explosive package. When the package weight is more than $10 \mathrm{~kg}$, the energy of downstream seismic waves will not increase with the increase of package weight. From the view of energy gain efficiency, the heavier the explosive package is, the lower the gain efficiency obtained by increasing the unit weight will be. Gain ratio is $67.5 \%$ when package weight increases from $1 \mathrm{~kg}$ to $2 \mathrm{~kg}$ as well as from $2 \mathrm{~kg}$ to $4 \mathrm{~kg}$. While package weight increases from $4 \mathrm{~kg}$ to $6 \mathrm{~kg}$, gain ratio is $25.4 \%$. When the weight of package is over $6 \mathrm{~kg}$, every $2 \mathrm{~kg}$ weight increase of the package only brings about $15 \%$ gain ratio. More over, once the package weight exceeds $10 \mathrm{~kg}$, increasing the package weight continuously will almost bring zero growth in energy gain efficiency.

The results above show that when explosion excitation is carried out with a single explosive package in a single excitation well in carbonate strata, it is infeasible to increase the vibration intensity and energy of the seismic waves transmitted downward by merely increasing the weight of standard explosive package.

In order to ensure that the increase in unit weight of explosive package can bring higher gain efficiency of the vibration intensity and energy of the seismic waves transmitted downward, the applicable weight range of a single standard explosive package should be $4 \mathrm{~kg} \sim 8 \mathrm{~kg}$.

\section{Research on the Critical Depth of Burial}

When the embedment depth of the explosive package in the rock body is too shallow, the energy of the explosion will spill out from the surface of the rock mass, forming a blasting funnel or the swelling of the rock surface. Although under this condition, the peak value of stress wave generated by the explosion will not change basically, the action time will be obviously reduced, which will result in a significant decrease of the energy of the downstream seismic waves.

Reflected waves formed from the free surface will superimpose with the direct explosion stress waves, which will affect the waveform characteristics of explosion stress waves. When the buried depth of the explosive package is greater than a certain critical value, stress wave caused by the explosion (attenuate to seismic waves beyond) has maximum energy in downstream direction and the characteristics of waveform will not be affected by the superimposition of the upper reflected waves. The minimum depth of embedment now is defined as the critical buried depth in explosion excitation.

This paper researches the critical depth of burial by changing the boundary conditions of the numerical models and the embedment depths of explosive package. Setting the weight of a single standard explosive package as $10 \mathrm{~kg}$, the upper surface of model as non-reflecting boundary and that the embedment depths 
of the explosive package are $2 \mathrm{~ms}$ and $4 \mathrm{~ms}$; And the upper surface of model as free boundary, the embedment depths of the explosive package are $2 \mathrm{~m}$, and 4, 6, 8, 10,12, 15, 18 and $22 \mathrm{~m}$ respectively, this research does calculations and analyses on these 11 situations. With the embedment depth of $2 \mathrm{~m}$, different boundary conditions, $1 \mathrm{~m}$ below explosive package, the monitoring point at radial distance of $4.3 \mathrm{~m}$, the calculated results of vibration velocity-time are shown in Fig.4. With the embedment depth of 4m, different boundary conditions, explosive package center, the monitoring point at radial distance of $4.3 \mathrm{~m}$, the calculated results of vibration velocity-time are shown in Fig.5.
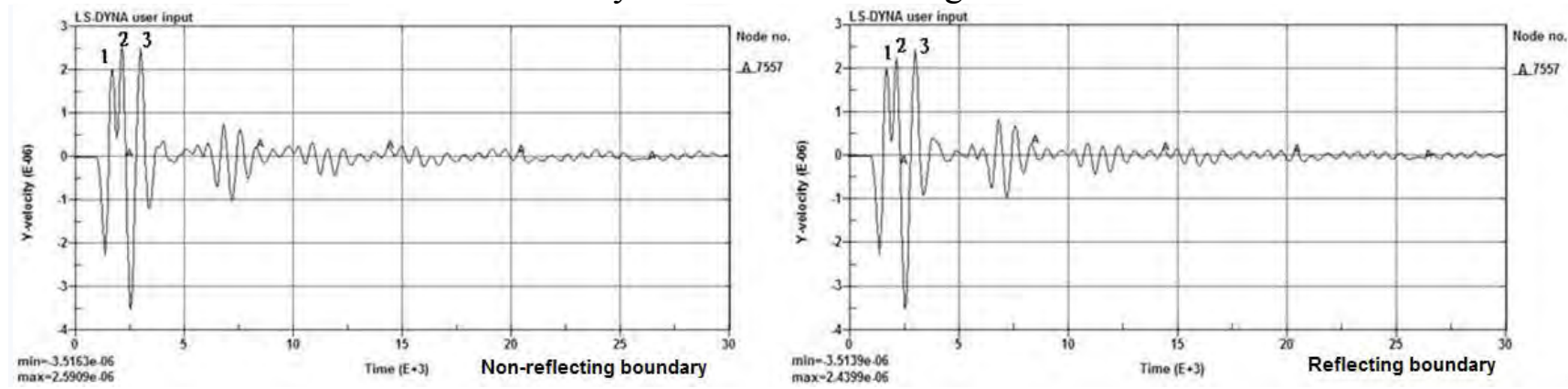

Fig. 4 Calculated Result of Vibration Velocity-time (Embedment depth of 2m, different boundary condition, $1 \mathrm{~m}$ below explosive package, the monitoring point at radial distance of $4.3 \mathrm{~m}$ )
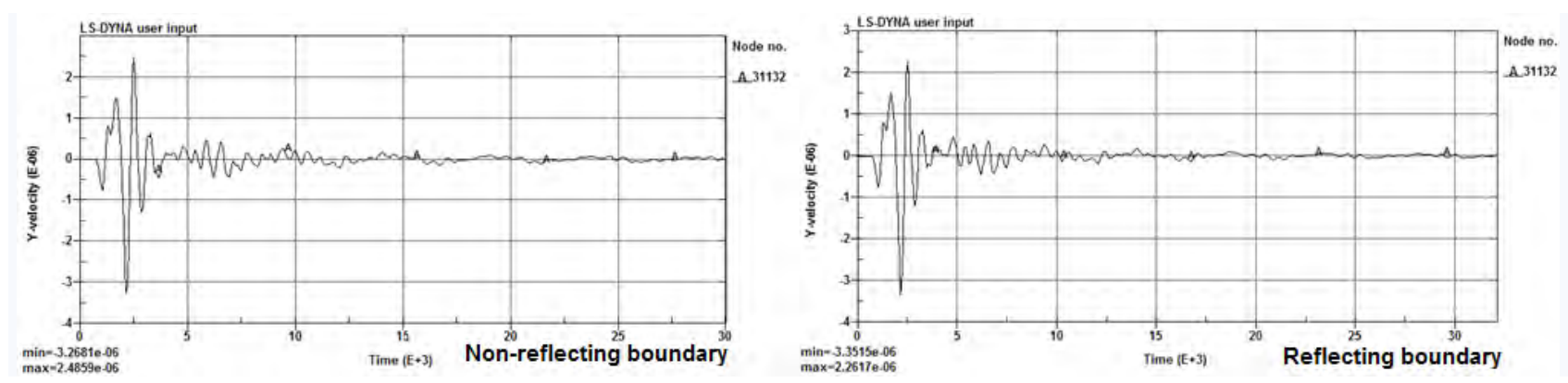

Fig. 5 Calculated Result of Vibration Velocity-time (Embedment depth of 4m, different boundary condition, explosive package center, the monitoring point at radial distance of $4.3 \mathrm{~m}$ )

As can be seen from Fig.4, under the embedment depth of $2 \mathrm{~m}$ and non-reflective boundary condition, the peak of vibration velocity in the waveform diagram appears before $2.5 \mathrm{~ms}$, while the peak in reflective boundary condition appears after $2.5 \mathrm{~ms}$. Thus, the reflected waves generated by the upper surface of the rock impact the main waveform of the downstream seismic waves, so the feature of the waveform changes.

As can be seen from Fig.5, when the embedment depth is $4 \mathrm{~m}$, the characteristics of vibration velocity waveforms do not change obviously in two different boundary conditions, just peak vibration velocity has some changes due to the impact of the boundary conditions.

Under the conditions of different embedment depths and the monitoring point in the same position in the model internal, results of vibration velocity peak are shown in Table 3. 1 \# monitoring point is located $1 \mathrm{~m}$ below the package, $2 \#$ monitoring point is located $5 \mathrm{~m}$ below the package and radial distances are $1 \mathrm{~m}$.

Tab. 3 Monitoring Points Results of Vibration Velocity Peak in the Same Position

\begin{tabular}{llllllllll}
\hline $\begin{array}{l}\text { embedment depth } \\
\text { (m) }\end{array}$ & 2 & 4 & 6 & 8 & 10 & 12 & 15 & 18 & 22 \\
\hline $\begin{array}{l}1 \# \text { monitoring point } \\
\text { vibration velocity } \\
\text { peak } \\
\text { (m/s) }\end{array}$ & 28.85 & 28.87 & 28.87 & 28.87 & 28.87 & 28.87 & 28.87 & 28.87 & 28.87 \\
\hline $\begin{array}{l}2 \# \text { monitoring point } \\
\text { vibration velocity } \\
\text { peak } \\
\begin{array}{l}(\mathrm{m} / \mathrm{s})\end{array}\end{array}$ & 4.93 & 4.88 & 4.88 & 4.88 & 4.88 & 4.88 & 4.88 & 4.88 & 4.88 \\
\hline
\end{tabular}


The results in Table 3 show that when the embedment depth is less than $4 \mathrm{~m}$, the reflected wave caused by upper free surface impacts vibration velocity peak of the downstream seismic wave. When the embedment depth is deeper than $4 \mathrm{~m}$, reflected wave generated by the rock upper free surface hardly influences vibration velocity peak of downstream seismic wave, i.e. downstream propagation of seismic wave is not influenced by the upper boundary condition, and the propagation rule tends to be stable.

According to the calculation results above, considering that in the actual production, the reflectance of strata interface is less than that of the free surface in numerical experiments, the critical depth of burial is $4 \sim 6 \mathrm{~m}$ below the bedrock surface when explosion excitation is carried out with a single explosive package in a single excitation well in carbonate strata

\section{Conclusion}

According to the results of the numerical simulation tests on explosion excitation carried out with a single explosive package in a single excitation well in carbonate strata, the vibration characteristics of the seismic waves generated by explosion of radius $2.5 \mathrm{~cm}$ standard cylindrical explosive package, we can get the following main conclusions.

1. It is infeasible to increase the vibration intensity and energy of the seismic waves transmitted downward by merely increasing the weight of standard explosive package.

2. When the embedment depth of standard explosive package is less than $4 \mathrm{~m}$, the reflected wave caused by upper free surface impacts the downstream seismic wave and may change its waveform characteristics. When the embedment depth is deeper than $4 \mathrm{~m}$, the downstream propagation of seismic wave is not influenced by the upper boundary condition, i.e. the propagation rule tends to be stable.

3. When explosion excitation is carried out with a single explosive package in a single excitation well in carbonate strata, the applicable weight range of a single standard explosive package should be $4 \mathrm{~kg} \sim$ $8 \mathrm{~kg}$.

4. The critical depth of burial of the standard explosive package in carbonate strata is $4 \sim 6 \mathrm{~m}$ below the bedrock surface.

\section{References}

[1]Ling yun.Analysis of charge size and charge type. OIL GEOPHYSICICAL PROSPECTING, 2001, 36(5): 584-590.

[2]Hongchao Shi, Ning Ding, Jichun Zhang, Analysis of vibration effects on surrounding rock for small clear distance tunnel under the dynamic action of blasting, BLASTING, 487X(2008)01-0074-05.

[3]Tan Shaoquan, The delay stack explosion technique and its applications, GEOPHYSICAL PROSPECTING FOR PETROLEUM, 1441(2003)04-0427-07.

[4]Tan Duowang, Chen Senhua,Liu Wenhan, Aapplication of finite element analysis in dynamics of explosion, EXPLOSION AND SHOCK WAVES, 1997, 340-346.

[5]Meyers M A.Dynamic Behavior of Materials,NewYork: John Wiley\&Sons, 1994. 152-178.

[6]Bangash M Y H.Impact and Explosion:Structural Analysis and Design. Great Britain: Black well Scientific Publication, 1993. 496-533

[7] Li Wenbin, Wang Xiao ing, Zhao Guozhi, He Yong,Study on Energy of Seismic Wave from Shock of Superimposed Seismic Source in Vertical Direction, Explosive Materials, 2004. 9-11

[8]Du Ping,Huang Dongding2,Wang Zeshan, Application of Low Detonation Velocity Explosive in Geologic Exploration, ACTA ARMAMENTARII, (2005)04-0465-04. 